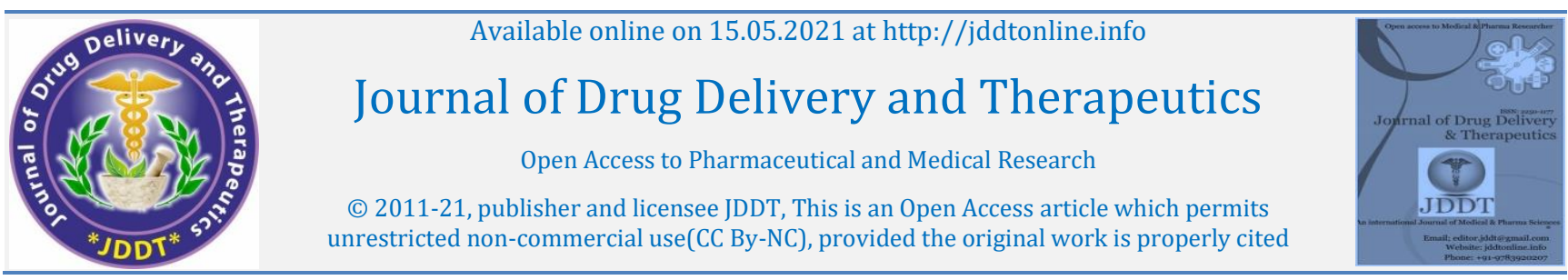

(C) 2011-21, publisher and licensee JDDT, This is an Open Access article which permits

Open Access Full Text Article

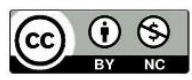

Review Article

\title{
Dietary Impact in Association to Risk of Cancer and their Anticancer Immune Response
}

\author{
Arslan Habib ${ }^{1}$, Zahid Hussain², Malik Shah Zaib Khalid ${ }^{3}$, Zeeshan Ashraf ${ }^{4}$, Ghulam Jaffar5, Aqsa Ashfaq ${ }^{6}$, \\ Muhammad Awais ${ }^{7}$, Muhammad Talha ${ }^{8}$
}

${ }^{1}$ Lab of Molecular Immunology, School of Life Sciences, Fudan University, Shanghai, China

${ }^{2}$ Department of Zoology, Division of Science \& Technology, University of Education, Lahore, Pakistan

${ }^{3}$ Institute of Zoology, University of the Punjab, Lahore, Pakistan

${ }^{4}$ Department of Fisheries \& Aquaculture, University of Veterinary and Animals Sciences, Lahore, Pakistan

${ }^{5}$ Department of Wildlife \& Ecology, University of Veterinary and Animals Sciences, Lahore, Pakistan

${ }^{6}$ Institute of Zoology, University of the Punjab, Lahore, Pakistan

${ }^{7}$ Department of Zoology, Division of Science \& Technology, University of Education, Lahore, Pakistan

${ }^{8}$ Department of Zoology, Division of Science \& Technology, University of Education, Lahore, Pakistan

\section{Article Info:

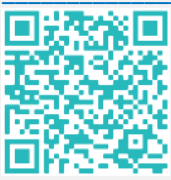 \\ Article History: \\ Received 28 March 2021 \\ Review Completed 21 April 2021 \\ Accepted 27 April 2021; \\ Available online 15 May 2021}

Cite this article as:

Habib A, Hussain Z, Khalid MSZ, Ashraf Z, Jaffar G, Ashfaq A, Awais M, Talha M, Dietary Impact in Association to Risk of Cancer and their Anticancer Immune Response, Journal of Drug Delivery and Therapeutics. 2021; 11(3):106-112

DOI: http://dx.doi.org/10.22270/jddt.v11i3.4826

\section{*Address for Correspondence:}

Arslan Habib, Lab of Molecular Immunology, School of Life Sciences, Fudan University, Shanghai, China. ORCID ID: https://orcid.org/0000-0001-5771-6411

\section{Abstract}

The imbalance between modulation of the cell proliferation and apoptosis results in abnormal cell production which ultimately leads to the cancerous condition. During the $21^{\text {st }}$ century, cancer is probably exceeded to infectious and other chronic diseases as the major cause of death in all countries. The increasing global prevalence ratio and a speedily rising population of cancer survivors focus on the ferocity of public health and economic challenges pretended this disease. This review summarizes the significant outcomes of dietary intake which can enhance the immune response and reduce the risk of cancer. The nutritional general mechanism of action to influence the immune function and the potential activity of anticancer immunotherapy are also studied. For several cancers immunotherapy has developed into standard treatment but considerably remains to be done to prolong the activity of its potential efficiency mainly to cancers that are unaffected within each indication. Although a higher consumption of plant foods like vegetables, fruits, legumes, nuts and whole grains has been suggested for cancer prevention, it has been undecided what is the prime amount of ingestion of these foods and whether particular subtypes are valuable. Several million premature mortalities can be prevented if a high intake of plant foods is adopted globally. Furthermore, for reducing the risk of different types of cancers and slow down their development many dietary products have been proven advantageous.

Keywords: Cancer, Immune system, Dietary items, Immunotherapy, Nutritional balance.

\section{Introduction}

Cancer is a major group of diseases observed by the abnormal cells proliferation away from their usual limitations that can then occupy adjoining parts of the body or extent to the other body organs. In 2019, almost 606,880 mortalities were reported in the USA due to the burden of cancer 1. During the $21^{\text {st }}$ century, cancer is probably exceeded the infectious and other chronic diseases as the major cause of death in all the countries 2. Due to the improvements in detection and treatment cancer incidence has fluctuated and survival ratios have enlarged in the USA 1. Therefore, increasing global prevalence ratio and a speedily rising population of cancer survivors focus the ferocity of the public health and economic challenges pretended this disease 2 . Public health strategies that are economical and coordinate cancer prevention via behavioral and living modifications are immediately desired 3. One of the adaptable lifestyle factors is a diet that has assembled consideration due to the increasing and significant indications of its capability to stimulus cancer risk. For reducing the risk of chronic diseases like type 2 diabetes, cardiovascular disease and cancer which are the possible risk of premature death globally 4 , the populations should adapt to intake a large number of plant products including vegetables, fruits, nuts, legumes and whole grains 5 . For instance, in 1991 in the United States, a program was launched with the name of $5 \mathrm{~A}$ Day for Better Health to enhance the consumption of vegetables and fruits to at least 5 servings/d ${ }^{6}$. In many other countries, similar movements have also been propelled 7 . Different epidemiological studies have shown such recommendations which have significantly exposed that higher consumption of vegetables and fruits reduced the risk of cardiovascular diseases and cancers 7 . Furthermore, higher consumption of whole grains and nuts is connected with a reduced risk of type 2-diabetes and coronary artery disease ${ }^{8-9}$. Historically, it was also observed that increased consumption of vegetables and fruits has a greater impact on the reduction of different cancerous conditions. Food, Nutrition and the Prevention of Cancer, the 
American Institute of Cancer Research and World Cancer Research Fund when announced their first report published in 1997 explained that there is significant evidence that increased consumption of vegetables and fruits have a significant influence on the reduction of cancers of the breast, mouth, larynx, esophagus, colon, rectum, stomach and bladder ${ }^{10}$. However, in the current decades, the evidence for the intake of vegetable and fruit advantages in cancer prevention became less significant as more potential cohort studies complied and exposed deficient or no correlations between vegetables and fruit consumption with the risk of several cancers 11-12. Besides, most accountable cancers for the death rates of women include stomach, cervical, lung and colorectal cancers. For effective anti-cancer therapy, only $30 \%$ of underprivileged countries are capable to provide associated facilities. Due to cancer treatment, the annual burden on the world economy is about US\$ 1.16 trillion. To reduce such an economic burden and increase the quality of life non-pharmacological methods such as steady physical activity and healthy nutritional habits should be encouraged which ultimately promoted conventional anti-cancer therapies. This review summarizes the significant outcomes of dietary intake which can enhance the immune response and reduce the risk of cancer. The nutritional general mechanism of action to influence the immune function and the potential activity of anticancer immunotherapy are also studied.

\section{Immunotherapy: Current status}

By presenting immunotherapy as a standard first and second-line modality checkpoint inhibitor therapy has carried a paradigm modification in the treatment of progressive cancer. The treatment with immunotherapy agents has a major benefit in the long-term significant potency as compared to other regular therapies like pathway inhibitors or chemotherapy. Though, only a subgroup of cancers inside each signals feedback to this therapy leaving the majority of patients unaffected by this potentially curative modality ${ }^{13}$. Recently, it was observed according to a degenerate method based on genetic instability that human cancers progress ensuing a severe selection bottleneck and leading to a trial and error development of oncogenic progressions or through a systematic stepwise addition of appropriate driver mutations. In the previous case, the immoral and chaotic method connected with increased immunogenicity of cancer cells while in the former cancer cells modified to grow without being accepted by the host immune surveillance 14 . Immunotherapy mechanism performs only in the perspective of immunogenic disorderly cancers but silent tumors are resistant. Only subgroup feedback to immunotherapy within immunogenic tumors and the reasons for the irregular consequences remain unidentified. Immune responsiveness in cancer can be determined by three types of factors: the environment, the genetic make-up of the host and the somatic profile of cancer cells 15. However, the maximum struggles to recognize immune responsiveness revolve around the somatic modifications of cancer cells and their influence on the host cells within the cancer microenvironment and in the transmission, comparatively slight information is accessible about the impact of environmental factors in regulating cancer interactions. Davis et al. recently discussed that clear variation is identified in the functions of the human immune according to simple variables like pathological, physiological and age status 16 . Different factors are involved which are related to variations in immune function. There are many methods in which nutrition can affect cancer cell proliferation via local or systemic effects within the tumor microenvironment (TME). Metabolic factors such as the increased metabolic activity of glucose associated with an increase in the level of lactate and the adenosine pathway, the decrease of tryptophan and arginine level, all have a significant impact on the immune mechanism inside the TME. It is also observed that the general metabolic methods influential deviation from ideal body weight extremely impacts the immune status. Moreover, important dietary components like vitamins may be regulated by the nutritional status and secondarily affect immune function 17 18.

\section{Correlation between immunity and nutrition}

Food signifies not only a potential component of body maintenance and growth but also involves some compounds which act as antigens. Particularly, throughout the lamina propria an innate and adaptive immune cell distributed or involves the secondary lymphoid organs like colonic lymphoid follicles and Peyer's patches can provoke robust feedback when triggered by food antigens. It has been observed that food intake leads to a situation of postprandial mild inflammation, which are not only local but also systemic ${ }^{19}$. In healthy volunteers after a 1-hour intake of a western-type hyper caloric breakfast serum levels of the inflammatory interleukin (IL)-17, cytokine, intensely increases 20. Among the control group individuals, this phenomenon was not observed who ingested breakfast along with polyphenols containing fruit juice. These components are recognized by a significant anti-inflammatory potential, which leads to the reduction of IL-17 serum values. Among the normal-weight children an experiment was conducted, they recommended a one-year Mediterranean diet (MD) compared to age complemented controls, who omitted health food endorsements, revealed variable immune profiles ${ }^{21}$. The outcomes of the experiment showed that the levels of IL-17 decreased while, salivary levels of the antiinflammatory cytokine, IL-10 increased. In another group of children who mostly intake "junk food" a considerable increase in IL-17 was detected. According to this, IL-10 is a cytokine primarily produced by FOXP3 + T regulatory (TREG) cells, which are convinced in the intestine by some dietary components, such as vitamins (A and D), polyunsaturated fatty acids (omega-3) and polyphenols. Immunosenescence is recognized as the failure of the immune mechanism with age which leads to the increased incidence of infections, autoimmune and neoplastic diseases in aging ${ }^{22}$. During the aging hypo-nutrition intensifies the previously impaired immunity, subsequently, aged people are commonly malnourished concerning unfortunate socio-economic conditions, mental illnesses and tooth loss 23. Most significantly, in the elderly lack of proteins and oligoelements regulates severe immune insufficiency, which can be serious. For example, among the elder's zinc deficiency is very common but undiagnosed, which leading to increased incidence of respiratory infections, $\mathrm{T}$ cell malfunction and reduced feedback to vaccination ${ }^{24}$. Thus, among the elders with zinc deficiency, zinc supplementation is very effective for the treatment of chronic diseases 25. Different studies suggested among the natural products the usage of red grape polyphenols to elder individuals restores weakened $\mathrm{T}$ cell functions and much effective during winter infections 26 . Furthermore, to restore innate and adaptive immunity among aged people the administration of probiotics and symbiotics is very effective, also enhancing the activity of intestinal microbiota which under normal situation plays their role in immune homeostasis along with balancing the symmetry between TREG cells and Th17 cells 27 . From circulation originating immune cells such as monocytes play a significant role in the tumour microenvironment 28 . Monocytes segregate into tumour-associated macrophages 
(TAMs), whose concentration completely associates with tumour progression ${ }^{29}$. T cytotoxic (Tc) cells are also present in extremely immunogenic tumours, which account for the tumour demolition or at least restraint the cancer growth. Therefore, TAMs and tumour cells produce suppressive cytokines which ultimately diminish $\mathrm{T}$ cell-mediated cytotoxicity ${ }^{30}$. Cancer cells as well as TAMs produce a group of pro-inflammatory cytokines like IL-6, TNF-alpha and IL-1 beta with the activation of transcription factors STAT 3 and NF-kB 31. Besides, TAMs employ carcinogenic effects, which producing growth factors 32 or releasing cytokines, such as IL-6, which demonstrate anti-apoptotic activities on cancer cells ${ }^{33}$. It should be highlighted, however, the immune intrudes within the tumour microenvironment are considered by natural plasticity and their functional coordination can be regressed by dissimilarity in the intratumour homeostasis prompted by several exogenous agents such as immunotherapy or environmentally associated factors such as co-morbidities, diet and microbiota ${ }^{34}$.

\section{Dietary products that increase the risk of cancer}

Several studies have explored the link between diet and certain cancers including breast, prostate and colorectal cancer 35. Some epidemiological evidence has shown that those who consume very fewer fruits and vegetables have a high risk of cancer in comparison with those who consume a good amount of the same. 128 out of 156 dietary studies reported statistically eloquent protective effects of consuming fruits and vegetables against cancer 36 . It indicates the inverse relationship between intake of fruits and vegetables with the risk of several cancers. Scientific investigations have found that exposure to many additives (nitrates and nitrites); food contaminants and dietary components have the carcinogenic potential 36 . People are failing to extract time for their health wellness. Even they do not hesitate to compromise their health while buying and eating packaged, processed, or artificially colored food. A study has revealed the occurrence of $80 \%$ of colorectal cancer due to dietary reasons ${ }^{37}$.

\section{Drinking water polluted with heavy metals}

In some Indian state's cities situated close to the Ganga River and its subsidiaries, high levels of heavy metals have been noted 38. Heavy metals (mercury, arsenic, lead, cadmium, chromium) induce the generation of reactive oxygen species which can cause DNA lesions and subsequently promote carcinogenesis 39. Histopathology reports and spectrophotometric assessment of gall bladder cancer patients living in those areas confirmed elevated levels of heavy metals like arsenic, mercury, lead, cadmium, and chromium in affected tissues and bile. These findings indicate the link of heavy metal with gall bladder cancer ${ }^{40}$.

\section{Processed foods}

A significant association was observed between the higher intake of pickled vegetables salted meat and the higher risk of gastric cancer in the Chinese population. Reduced intake of salt processed foods may reduce the chances of getting gastric, colon, rectum, pancreas, lung, bladder cancer 41. High-temperature processing, barbecuing of meat initiates a reaction between amino acids and sugars (Maillard reaction) that results in the production of heterocyclic amines (HACs) like 8-dimethyl imidazole quinoxaline (MeIQx) and the 2Amino-1-methyl6 phenylimidazo pyridine (PhIP) which are classified as potentially carcinogenic compound for human. Incomplete combustion of oil or cooking food by smoking produces polycyclic aromatic hydrocarbons (PHAs) like benzopyrene which is a potential carcinogen. DNA mutation is the suggested reason for carcinogenesis caused by PHAs and HACs 42

\section{Food dyes}

People are more affectionate for colorful food allocations but they are not aware of possible risks. But food dyes like Blue1, Blue2, Citrus Red2, Green3, Orange B, Red3 and Yellow6 have been found to cause kidney, thyroid, brain, adrenal, bladder and testicular tumors in rodent studies ${ }^{43}$. Clinical studies are needed to investigate the effects on humans.

\section{Fast foods}

Fried fast foods, sweetened drinks and the other foods with a high glycemic index are noted to increase the risk of colorectal cancer ${ }^{44}$. It has been investigated that high fatcontaining fast food consumption ultimately causes the possible increase of polycyclic aromatic hydrocarbons (PAHs) and such fats potentially affected the gastrointestinal tract of the body ${ }^{45}$. These findings point towards increasing the serious risk of the development of cancer with a frequency of fast-food intake.

\section{Aflatoxins}

These are toxic metabolites of certain fungi. Aspergillus flavus is one of the famous sources of aflatoxin that can infect many nuts and grains. Milk produced by mammals eating this infected foodstuff can pass aflatoxins to their infants ${ }^{46}$. The Department of food safety and zoonoses of the World Health Organization in 2018 published a report that people who get exposed to aflatoxin B1 for the long term become more vulnerable to get suffered from liver and kidney cancer 47-48.

\section{Acetaldehyde}

Humans may get acetaldehyde exposure from various foods, metabolism of ethanol. Binding to DNA acetaldehyde forms stable DNA adducts and also interferes with DNA repair processes which may promote carcinogenesis. With sound evidence, heavy drinkers are known to be highly vulnerable to mucosal hyperproliferation of the upper aerodigestive tract, large intestine and cancers of the upper respiratory tract 49 .

\section{Dietary products that reduce the risk of cancer}

\section{Foods containing 0mega-3 fatty acids}

Nowadays, several cancer researchers have started exploring apoptosis (natural cell death) as a target for anticancer therapy and they have noted overexpression of antiapoptotic proteins and under-expression of proapoptotic proteins in cancer cases ${ }^{50}$. Reports also claim that disturbed apoptosis circuitry is highly associated with oncogenicity 51 . PUFAs such as omega-3 fatty acids including Eicosapentaenoic acid (EPA) and docosahexaenoic acid (DHA) can reduce the proliferation of cancer cells and induce apoptosis both invivo and in-vitro. Furthermore, these polyunsaturated fatty acids are found valuable for cancer prevention and improving the efficacy of certain antineoplastic drugs ${ }^{52-53}$.

\section{Capsaicin}

Pungent phytochemical capsaicin present in peppers (widely used spices) is well known for having anti-oxidant and antiinflammatory potential ${ }^{54}$. Capsaicin has been explored and proved to have anticancer properties by altering the expression of some genes involved in angiogenesis, cancer cell survival and growth arrest 55. Capsaicin strengthens the fight against human glioma 56 , myeloma 56 , osteosarcoma 57 and colorectal 58 , lung 59 , bladder 60 , stomach 61 cancers by accelerating apoptosis rate 62 . 


\section{Cruciferous vegetables}

These vegetables such as Brussels sprouts, Bok choy, Cauliflower, Cabbage, Broccoli, belong to the family Cruciferae or Brassicaceae. Cruciferous vegetables are major sources of sulfur-associated compounds like glucosinolates and hydrolysis of these compounds during chopping and chewing of cruciferous vegetables result in products like indole-3-carbinol (I3C) and isothiocyanates ${ }^{63}$.

\section{Olive oil}

It is a blend of oleic acid, linoleic acid, secoiridoids, squalene, tyrosol, hydroxytyrosol (HT), lignans, flavonoids, triterpenes, $\beta$-sitosterol 64. The refining process makes the olive oil lacking polyphenols, vitamins, and phytosterols 65 . And high abundance of polyphenols is evident in extra virgin olive oil 66. Extra virgin olive oil is obtained from olives by pressing them without heat and chemical treatment. In the Mediterranean region olives are freely consumed and olive oil is the cooking fat of choice; and epidemiological studies relate this liberal consumption of olive oil with significantly fewer incidences of colorectal, breast and skin cancer in this region. Furthermore, squalene (abundantly found in Olive oil) is known for the tumor-inhibiting property 67.

Table 1: Different compounds present in cruciferous vegetables to reduce the risk of cancer

\begin{tabular}{lll}
\hline Compounds & Mechanism & Cell lines \\
\hline $\begin{array}{l}\text { Indole-3 carbinol } \\
\text { (I3C) }\end{array}$ & $\begin{array}{l}\text { G1 cell cycle termination PC-3 cells due to } \\
\text { variations occurred in G1 cell cycle proteins }\end{array}$ & Human prostate cancer cell line PC-3 \\
$\begin{array}{l}\text { Indole-3 carbinol } \\
\text { (I3C) }\end{array}$ & $\begin{array}{l}\text { Inhibits protein kinase B/Akt and Influence } \\
\text { apoptosis }\end{array}$ & Human breast tumor cell line MDA MB468 \\
$\begin{array}{l}\text { Indole-3 carbinol } \\
\text { (I3C) }\end{array}$ & $\begin{array}{l}\text { Reactivation of a potent tumor suppressor gene } \\
\text { PTEN }\end{array}$ & $\begin{array}{l}\text { Human cell lines, Wwp1-/- mice and its } \\
\text { paired Wwp1+/+ mice }\end{array}$ \\
$\begin{array}{l}\text { 3,3'- } \\
\text { diindolylmethane }\end{array}$ & $\begin{array}{l}\text { Rises of p21 protein and mRNA levels and induce } \\
\text { (DIM) }\end{array}$ & $\begin{array}{l}\text { Human breast adenocarcinoma cell } \\
\text { lines MCF-7 (estrogen dependent) and } \\
\end{array}$ \\
\end{tabular}

Table 2: Capsaicin cancer preventing mechanism of actions

\begin{tabular}{ll}
\hline Mechanism of actions & Cell lines \\
\hline Stimulation of Fas/CD95 mediated apoptosis & Human urothelial cancer cells \\
$\begin{array}{l}\text { Induces TRPV6 receptor and calpain pathway } \\
\text { mediated apoptosis }\end{array}$ & $\begin{array}{l}\text { Human small cell lung cancer cell lines (NCI-H82, NCI-H69, } \\
\text { DMS53, DMS114) }\end{array}$ \\
$\begin{array}{l}\text { Stimulation of TRPV1 vanilloid receptor-mediated } \\
\text { apoptosis }\end{array}$ & Human glioma cells \\
$\begin{array}{l}\text { Cell cycle arrest at G2/M phase } \\
\text { Degeneracy of mitochondrial membrane potential }\end{array}$ & Human KB cancer cells \\
\hline
\end{tabular}

Table 3: Olive oil compounds anti-cancer mechanism of action

\begin{tabular}{lllc}
\hline Olive compounds & Biological effects & Cell lines & Ref. \\
\hline Hydroxytyrosol & Apoptosis induction & Estrogen receptor negative SKBR3 breast cancer cell & 78 \\
Oleuropein & Reduced angiogenesis & Human umbilical vein endothelial cells & 78 \\
Oleocanthal & $\begin{array}{l}\text { Inhibition of acid } \\
\text { sphingomyelinase }\end{array}$ & Human pancreas adenocarcinoma, BxPC3 cells & 79 \\
Oleocanthal & $\begin{array}{l}\text { Cytotoxicity } \\
\text { Induction of apoptosis }\end{array}$ & Human breast cancer MDA-MB-231, MCF-7, and T-47D cells & 80 \\
Oleuropein & Cell cycle delay at S phase & MDA-MB-231 and MCF-7 human breast cancer cell lines & 81 \\
\hline
\end{tabular}




\section{Garlic and Onions}

A large number of epidemiological studies have provided strong evidence in favor of cancer (especially gastrointestinal and esophageal) preventing effects of Allium genus vegetables including garlic and onions 68 . Heating badly influences the anticancer property of garlic as it has been noted that microwaving for 60 seconds or 45 minutes oven heating of uncrushed garlic leads to a significant weakening of the anticancer effect exhibited by garlic ${ }^{69}$. A 2016 study on Chinese lung cancer patients suggested the significant inverse association of raw garlic intake with the development of lung cancer in a dose-dependent manner when compared to no intake ${ }^{70}$. It has been proved that garlic extract augments the anticancer effect of existing antineoplastic drugs such as cisplatin, docetaxel and gemcitabine.

\section{Lycopene foods}

Lycopene (a red carotenoid) is abundantly found in ripe tomatoes, red watermelon and grapefruits. It prevents oxidative damage of DNA by fighting against free radicles and in this way, it slows the transformation of normal cells to cancerous cells. Voluminous evidence about its anti-oxidant, anti-proliferative, pro-apoptotic activities against oral and prostate cancer are available ${ }^{70}$.

Table 4: Lycopene cancer preventing mechanism of actions

\begin{tabular}{|c|c|c|}
\hline Mechanism of actions & Cell lines & Ref. \\
\hline $\begin{array}{l}\text { Cell cycle arrest, rise in apoptosis, inhibition of cell } \\
\text { growth }\end{array}$ & $\begin{array}{l}\text { Human prostate, breast, colon, liver, larynx, } \\
\text { and cervical cancer lines }\end{array}$ & 82 \\
\hline Cell growth arrest and apoptosis & $\begin{array}{l}\text { Androgen independent DU145, PC-3, and } \\
\text { androgen-dependent LNCaP human prostate } \\
\text { cancer cells }\end{array}$ & 83 \\
\hline $\begin{array}{l}\text { G0-G1 cell cycle arrest, apoptosis via significant suppression of } \\
\text { ERK (extracellular signal-regulated kinase) signalling pathway }\end{array}$ & Human gastric HGC-27 cell line & 84 \\
\hline
\end{tabular}

\section{Conclusion}

The outcomes of the current study concluded that the increased intake of different processed food, drinking water containing heavy metals; food colors and infected nuts are the possible risk factors of several cancers. Cancer patient's histopathological analysis exposed the correlation of dietary intake and cancer risk. Higher intake of plant foods such as vegetables, fruits, legumes, nuts and whole grains are of greater importance for reducing the risk of various cancers and premature deaths. The current outcome strongly recommends a higher intake of fruits and vegetables. While the possible mechanism that may influence the immune system and thus cancer growth and feedback to immunotherapy agents have been exposed, insufficient information is available about how they may influence and regulate the therapies since limitations relating dietary habits to clinical consequence during immunotherapy are not regularly included. Comprehensive information about the diet and nutritional status should be measured in association with immunotherapy trials. A massive campaign should be launched to aware the community of the importance of diet and routine lifestyle for increasing immunity against cancer. For the dietary anticancer and carcinogenic potential extensive quantitative examination should be performed on a large scale.

\section{Authors Contribution:}

All the authors are supported in the manuscript formation, data analysis, reviewing of the final data. All of them also supported the technical issues and approved the final version of the manuscript.

\section{Funding:}

Authors received no specific funding for this work

\section{Conflict of Interest:}

The authors have no conflicts of interest to disclose.

\section{References}

1. Siegal R, Miller KD, Jemal A. Cancer statistics, 2012. CA: A Cancer Journal for Clinicians. 2014; 64(1):9-29.

2. Bray F, Ferlay J, Soerjomataram I, Siegel RL, Torre LA, Jemal A Global cancer statistics 2018: GLOBOCAN estimates of incidence and mortality worldwide for 36 cancers in 185 countries. CA: A Cancer Journal for Clinicians. 2018; 68(6):394-424.

3. Habib A, Jaffar G, Khalid MS, et al. Risk Factors Associated with Prostate Cancer. Journal of Drug Delivery and Therapeutics. 2021; 11(2):188-193.

4. Marmot M, Atinmo T, Byers $\mathrm{T}$, et al. World Cancer Research Fund/American Institute of CAncer REsearch, Food, Nutrition, Physical Activity, and the Prevention of Cancer: a Global Perspective. 2007.

5. Lallukka T, Millear A, Pain A, Cortinovis M, Giussani G. GBD 2015 mortality and causes of death collaborators. Global, regional, and national life expectancy, all-cause mortality, and cause-specifi c mortality for 249 causes of death, 1980-2015: a systematic analysis for the global burden of disease study 2015. Lancet Oncoloy. 2017; 389(10064):E1-E1.

6. Foerster SB, Kizer KW, DiSogra LK, Bal DG, Krieg BF, Bunch KL. California's “5 a day-for better health!" campaign: An innovative population-based effort to effect large-scale dietary change. American Journal of Preventive Medicine. 1995; 11(2):124-131

7. Bere E, Hilsen M, Klepp K-I. Effect of the nationwide free school fruit scheme in Norway. British Journal of Nutrition. 2010; 104(4):589-594.

8. Habib A, Anjum KM, Shehzad A, Imran M, Ashraf Z, Ramzan M. Outbreak of COVID-19 pandemic in Pakistan and the current scenario. The Applied Biology and Chemistry Journal. 2020; $1(2): 67-71$.

9. Habib A, Principe UE, Ashraf Z, Imran M. Epidemiology of Rabies and the Control Challenges. Biotica Research Today. 2020; 2(11):1201-1204.

10. Michels KB, Giovannucci E, Joshipura KJ, et al. Prospective study of fruit and vegetable consumption and incidence of colon and rectal cancers. Journal of the National Cancer Institute. 2000; 92(21):1740-1752.

11. Terry P, Giovannucci E, Michels KB, et al. Fruit, vegetables, dietary fiber, and risk of colorectal cancer. Journal of the National Cancer Institute. 2001; 93(7):525-533. 
12. Van Gils $\mathrm{CH}$, Peeters $\mathrm{PH}$, Bueno-de-Mesquita $\mathrm{HB}$, et al. Consumption of vegetables and fruits and risk of breast cancer. Jama. 2005; 293(2):183-193.

13. Emens LA, Ascierto PA, Darcy PK, et al. Cancer immunotherapy: opportunities and challenges in the rapidly evolving clinical landscape. European Journal of Cancer. 2017; 81:116-129.

14. Masucci GV, Cesano A, Eggermont A, et al. The need for a network to establish and validate predictive biomarkers in cancer immunotherapy. Journal of Translational Medicine. 2017;15(1):1-10.

15. Wang E, Uccellini L, Marincola FM. A genetic inference on cancer immune responsiveness. Oncoimmunology. 2012; 1(4):520-525.

16. Davis MM, Tato CM, Furman D. Systems immunology: just getting started. Nature Immunology. 2017; 18(7):725.

17. Renner K, Singer K, Koehl GE, et al. Metabolic hallmarks of tumor and immune cells in the tumor microenvironment. Frontiers in Immunology. 2017; 8:248.

18. De Rosa V, Di Rella F, Di Giacomo A, Matarese G. Regulatory T cells as suppressors of anti-tumor immunity: role of metabolism. Cytokine \& Growth Factor Reviews. 2017; 35:15-25.

19. Morabito G, Kucan P, Serafini M. Prevention of postprandial metabolic stress in humans: role of fruit-derived products Endocrine, Metabolic \& Immune Disorders-Drug Targets. 2015; 15(1):46-53

20. Peluso I, V Villano D, A Roberts S, et al. Consumption of mixed fruit-juice drink and vitamin $C$ reduces postprandial stress induced by a high fat meal in healthy overweight subjects Current Pharmaceutical Design. 2014; 20(6):1020-1024.

21. Casas R, Sacanella E, Estruch R. The immune protective effect of the Mediterranean diet against chronic low-grade inflammatory diseases. Endocrine, Metabolic \& Immune Disorders-Drug Targets. 2014; 14(4):245-254.

22. Campisi J. Aging, cellular senescence, and cancer. Annual Review of Physiology. 2013; 75:685-705.

23. Haase $H$, Rink L. The immune system and the impact of zinc during aging. Immunity \& Ageing. 2009; 6(1):1-17.

24. Prasad AS. Discovery of human zinc deficiency: its impact on human health and disease. Advances in Nutrition. 2013; 4(2):176-190.

25. Mocchegiani E, Costarelli L, Giacconi R, Piacenza F, Basso A, Malavolta M. Zinc, metallothioneins and immunosenescence: effect of zinc supply as nutrigenomic approach. Biogerontology. 2011; 12(5):455-465.

26. Magrone T, Pugliese V, Fontana S, Jirillo E. Human use of Leucoselect $\AA$ Phytosome $\AA$ with special reference to inflammatory-allergic pathologies in frail elderly patients. Current Pharmaceutical Design. 2014; 20(6):1011-1019.

27. Amati L, Marzulli G, Martulli M, et al. Administration of a synbiotic to free-living elderly and evaluation of serum cytokines. A pilot study. Current Pharmaceutical Design. 2010; 16(7):854-858.

28. Marelli G, Sica A, Vannucci L, Allavena P. Inflammation as target in cancer therapy. Current Opinion in Pharmacology. 2017 35:57-65.

29. Coussens LM, Zitvogel L, Palucka AK. Neutralizing tumorpromoting chronic inflammation: a magic bullet? Science. 2013; 339(6117):286-291

30. Mantovani A, Allavena P, Sica A, Balkwill F. Cancer-related inflammation. Nature. 2008; 454(7203):436-444.

31. Tudek B, Zdżalik-Bielecka D, Tudek A, Kosicki K, Fabisiewicz A, Speina E. Lipid peroxidation in face of DNA damage, DNA repair and other cellular processes. Free Radical Biology and Medicine. 2017; 107:77-89.

32. Condeelis J, Pollard JW. Macrophages: obligate partners for tumor cell migration, invasion, and metastasis. Cell. 2006; 124(2):263-266

33. Mantovani A, Romero P, Palucka AK, Marincola FM. Tumour immunity: effector response to tumour and role of the microenvironment. The Lancet. 2008; 371(9614):771-783.

34. Iida N, Dzutsev A, Stewart CA, et al. Commensal bacteria control cancer response to therapy by modulating the tumor microenvironment. Science. 2013; 342(6161):967-970.

35. Baena R, Salinas P. Diet and colorectal cancer. Maturitas. 2015 80(3):258-264.

36. Block G, Patterson B, Subar A. Fruit, vegetables, and cancer prevention: a review of the epidemiological evidence. Nutrition and Cancer. 1992; 18(1):1-29.
37. Bingham S. Diet and colorectal cancer prevention. Biochemical Society Transactions. 2000; 28(2):12-16.

38. Unisa S, Jagannath P, Dhir V, Khandelwal C, Sarangi L, Roy TK Population-based study to estimate prevalence and determine risk factors of gallbladder diseases in the rural Gangetic basin of North India. Hepato-Pancreato-Biliary Association. 2011; 13(2):117-125.

39. Yuan W, Yang N, Li X. Advances in understanding how heavy metal pollution triggers gastric cancer. BioMed Research International. 2016; 2016.

40. Chhabra D, Oda K, Jagannath $\mathrm{P}$, Utsunomiya $\mathrm{H}$, Takekoshi S Nimura Y. Chronic heavy metal exposure and gallbladder cancer risk in India, a comparative study with Japan. Asian Pacific Journal of Cancer Prevention. 2012; 13(1):187-190.

41. Lin S-H, Li Y-H, Leung K, Huang C-Y, Wang X-R. Salt processed food and gastric cancer in a Chinese population. Asian Pacific Journal of Cancer Prevention. 2014; 15(13):5293-5298.

42. Cascella M, Bimonte S, Barbieri A, et al. Dissecting the mechanisms and molecules underlying the potential carcinogenicity of red and processed meat in colorectal cancer (CRC): an overview on the current state of knowledge. Infectious Agents and Cancer. 2018; 13(1):1-8.

43. Kobylewski S, Jacobson MF. Toxicology of food dyes. International Journal of Occupational and Environmental Health 2012; 18(3):220-246.

44. Pietrzyk Ł. Food properties and dietary habits in colorectal cancer prevention and development. International Journal of Food Properties. 2017; 20(10):2323-2343.

45. Laher J, Rigler M, Vetter R, Barrowman J, Patton J. Similar bioavailability and lymphatic transport of benzo (a) pyrene when administered to rats in different amounts of dietary fat. Journal of Lipid Research. 1984; 25(12):1337-1342.

46. Abnet CC. Carcinogenic food contaminants. Cancer investigation 2007;25(3):189-196.

47. Habib A, Jaffar G, Khalid M. Letter to Editor: Challenges in the Development of Hepatitis C Vaccine. International Journal of Biomedical Investigation. 2020; 3: 127.

48. Hamid AS, Tesfamariam IG, Zhang Y, Zhang ZG. Aflatoxin B1induced hepatocellular carcinoma in developing countries: Geographical distribution, mechanism of action and prevention. Oncology Letters. 2013; 5(4):1087-1092.

49. Simanowski U, Homann N, Knühl M, et al. Increased rectal cell proliferation following alcohol abuse. Gut. 2001; 49(3):418-422.

50. Pfeffer CM, Singh AT. Apoptosis: a target for anticancer therapy. International Journal of Molecular Sciences. 2018; 19(2):448.

51. Hanahan D, Weinberg RA. Hallmarks of cancer: the next generation. Cell. 2011; 144(5):646-674.

52. D'Eliseo D, Velotti F. Omega-3 fatty acids and cancer cell cytotoxicity: implications for multi-targeted cancer therapy Journal of Clinical Medicine. 2016; 5(2):15.

53. Moloudizargari M, Mortaz E, Asghari MH, Adcock IM, Redegeld FA, Garssen J. Effects of the polyunsaturated fatty acids, EPA and DHA, on hematological malignancies: a systematic review. Oncotarget. 2018; 9(14):11858.

54. Zimmer AR, Leonardi B, Miron D, Schapoval E, de Oliveira JR, Gosmann G. Antioxidant and anti-inflammatory properties of Capsicum baccatum: from traditional use to scientific approach Journal of Ethnopharmacology. 2012; 139(1):228-233.

55. Lin R-J, Wu I-J, Hong J-Y, et al. Capsaicin-induced TRIB3 upregulation promotes apoptosis in cancer cells. Cancer Management and Research. 2018; 10:4237.

56. Amantini C, Mosca M, Nabissi M, et al. Capsaicin-induced apoptosis of glioma cells is mediated by TRPV1 vanilloid receptor and requires p38 MAPK activation. Journal of Neurochemistry. 2007; 102(3):977-990.

57. Ying $\mathrm{H}$, Wang Z, Zhang $\mathrm{Y}$, et al. Capsaicin induces apoptosis in human osteosarcoma cells through AMPK-dependent and AMPK-independent signaling pathways. Molecular and Cellular Biochemistry. 2013; 384(1):229-237.

58. Lee S-H, Richardson RL, Dashwood RH, Baek SJ. Capsaicin represses transcriptional activity of $\beta$-catenin in human colorectal cancer cells. The Journal of Nutritional Biochemistry. 2012; 23(6):646-655.

59. Lee Y-H, Chen H-Y, Su LJ, Chueh PJ. Sirtuin 1 (SIRT1) deacetylase activity and NAD+/NADH ratio are imperative for capsaicinmediated programmed cell death. Journal of Agricultural and Food Chemistry. 2015; 63(33):7361-7370. 
60. Amantini C, Ballarini P, Caprodossi S, et al. Triggering of transient receptor potential vanilloid type 1 (TRPV1) by capsaicin induces Fas/CD95-mediated apoptosis of urothelial cancer cells in an ATM-dependent manner. Carcinogenesis. 2009; 30(8):1320-1329.

61. Chow J, Norng M, Zhang J, Chai J. TRPV6 mediates capsaicininduced apoptosis in gastric cancer cells-Mechanisms behind a possible new "hot" cancer treatment. Biochimica et Biophysica Acta (BBA)-Molecular Cell Research. 2007; 1773(4):565-576.

62. Ito $\mathrm{K}$, Nakazato $\mathrm{T}$, Yamato $\mathrm{K}$, et al. Induction of apoptosis in leukemic cells by homovanillic acid derivative, capsaicin, through oxidative stress: implication of phosphorylation of p53 at Ser-15 residue by reactive oxygen species. Cancer Research. 2004; 64(3):1071-1078.

63. Lee Y-R, Chen M, Lee JD, et al. Reactivation of PTEN tumor suppressor for cancer treatment through inhibition of a MYCWWP1 inhibitory pathway. Science. 2019; 364(6441).

64. Borzì AM, Biondi A, Basile F, Luca S, Vicari ESD, Vacante M. Olive oil effects on colorectal cancer. Nutrients. 2019; 11(1):32.

65. Kamm W, Dionisi F, Hischenhuber C, Engel K-H. Authenticity assessment of fats and oils. Food Reviews International. 2001; 17(3):249-290.

66. Kalogeropoulos N, Tsimidou MZ. Antioxidants in Greek virgin olive oils. Antioxidants. 2014; 3(2):387-413.

67. Owen R, Haubner R, Würtele G, Hull W, Spiegelhalder B, Bartsch $\mathrm{H}$. Olives and olive oil in cancer prevention. European Journal of Cancer Prevention. 2004; 13(4):319-326.

68. Zong J, Martirosyan DM. Anticancer effects of garlic and garlicderived bioactive compounds and its potential status as functional food. Bioactive Compounds in Health and Disease. 2018; 1(2):16-35.

69. Song K, Milner JA. The influence of heating on the anticancer properties of garlic. The Journal of Nutrition. 2001; 131(3):1054S-1057S.

70. Myneni AA, Chang S-C, Niu R, et al. Raw garlic consumption and lung cancer in a Chinese population. Cancer Epidemiology and Prevention Biomarkers. 2016; 25(4):624-633.

71. Chinni SR, Li Y, Upadhyay S, Koppolu PK, Sarkar FH. Indole-3carbinol (I3C) induced cell growth inhibition, G1 cell cycle arrest and apoptosis in prostate cancer cells. Oncogene. 2001; 20(23):2927-2936.

72. Howells LM, Gallacher-Horley B, Houghton CE, Manson MM, Hudson EA. Indole-3-carbinol Inhibits Protein Kinase B/Akt and Induces Apoptosis in the Human Breast Tumor Cell Line MDA MB468 but not in the Nontumorigenic HBL100 Line 1 Supported by the United Kingdom Medical Research Council. These data have been published in a preliminary form as an abstract. Molecular Cancer Therapeutics. 2002; 1(13):1161-1172.
73. Hong C, Kim H-A, Firestone GL, Bjeldanes LF. 3, 3'Diindolylmethane (DIM) induces a G1 cell cycle arrest in human breast cancer cells that is accompanied by Sp1-mediated activation of p21WAF1/CIP1 expression. Carcinogenesis. 2002; 23(8):1297-1305.

74. Amantini C, Ballarini P, Caprodossi S, et al. Triggering of transient receptor potential vanilloid type 1 (TRPV1) by capsaicin induces Fas/CD95-mediated apoptosis of urothelial cancer cells in an ATM-dependent manner. Carcinogenesis. 2009; 30(8):1320-1329.

75. Lau JK, Brown KC, Dom AM, et al. Capsaicin induces apoptosis in human small cell lung cancer via the TRPV6 receptor and the calpain pathway. Apoptosis. 2014; 19(8):1190-1201.

76. Amantini C, Mosca M, Nabissi M, et al. Capsaicin-induced apoptosis of glioma cells is mediated by TRPV1 vanilloid receptor and requires p38 MAPK activation. Journal of Neurochemistry. 2007; 102(3):977-990.

77. Lin C-H, Lu W-C, Wang C-W, Chan Y-C, Chen M-K. Capsaicin induces cell cycle arrest and apoptosis in human KB cancer cells. BMC Complementary and Alternative Medicine. 2013; 13(1):1-9.

78. Chimento A, Casaburi I, Rosano C, et al. Oleuropein and hydroxytyrosol activate GPER/GPR 30-dependent pathways leading to apoptosis of ER-negative SKBR 3 breast cancer cells. Molecular Nutrition \& Food Research. 2014; 58(3):478-489.

79. LeGendre 0, Breslin PA, Foster DA. (-)-Oleocanthal rapidly and selectively induces cancer cell death via lysosomal membrane permeabilization. Molecular \& Cellular Oncology. 2015; 2(4):1006077.

80. Elamin $\mathrm{MH}$, Daghestani MH, Omer SA, et al. Olive oil oleuropein has anti-breast cancer properties with higher efficiency on ERnegative cells. Food and Chemical Toxicology. 2013; 53:310-316.

81. Khanfar MA, Bardaweel SK, Akl MR, El Sayed KA. Olive oilderived oleocanthal as potent inhibitor of mammalian target of rapamycin: biological evaluation and molecular modeling studies. Phytotherapy Research. 2015; 29(11):1776-1782.

82. Teodoro AJ, Oliveira FL, Martins NB, de Azevedo Maia G, Martucci RB, Borojevic R. Effect of lycopene on cell viability and cell cycle progression in human cancer cell lines. Cancer Cell International. 2012; 12(1):1-9.

83. Tang L, Jin T, Zeng X, Wang J-S. Lycopene inhibits the growth of human androgen-independent prostate cancer cells in vitro and in BALB/c nude mice. The Journal of Nutrition. 2005; 135(2):287-290.

84. Zhang B, Gu Y. Low expression of ERK signaling pathway affecting proliferation, cell cycle arrest and apoptosis of human gastric HGC-27 cells line. Molecular Biology Reports. 2014; 41(6):3659-3669. 